\title{
Assessment of Ecotourism Travel Risk on Word-of-Mouth: Via Fuzzy Set Perspective
}

\author{
${ }^{1}$ Fangyi Liu, ${ }^{2}$ Cheng-Hsi Fang, ${ }^{3}$ Hsueh-Lan Chan and ${ }^{3}$ Tom Meng-Yen Lin \\ ${ }^{1}$ Department of Marine Leisure Management, National Kaohsiung Marine University, \\ No.142, Haijhuan Rd., Nanzih Dist., Kaohsiung City 811, (R.O.C.), Taiwan \\ ${ }^{2}$ Department of Marketing and Distribution, ChienHsin University of Science and Technology, \\ No. 229 Jianxing Rd., Zhongli City, Taoyuan County 320, (R.O.C.), Taiwan \\ ${ }^{3}$ Department of Business Administration, National Taiwan University of Science and Technology, \\ No.43, Sec.4, Keelung Rd., Taipei City 106, (R.O.C.), Taiwan
}

Received 2012-06-22, Revised 2012-09-04; Accepted 2013-05-31

\begin{abstract}
Because of the subjective cognition on Word-Of Mouth (WOM) influence and the fuzziness on perceived-risk judgment, perceived risk in WOM Influence is a venture variable, which cannot be measured directly. The aim of this study is to define the mathematics meaning of the influence and develop a new fuzzy set method to build the influence membership function to exactly measure the perceived risk in WOM influence. From the fuzzy synthetic index of WOM influence, we can understand the membership grade for each influence factor, which reflects the WOM receivers' preference cognition and value. Finally, we use the Taiwan consumers of the ecotourism as an example to do empirical study. The result shows that the financial and physical risks attributes in WOM are higher and more significant. This implies that consumers have the characteristic of higher perceived risk in WOM and they prefer the averse strategy of buying the ecotourism assurance.
\end{abstract}

Keywords: Word-of-Mouth, Perceived Risk, Ecotourism, Fuzzy Set

\section{INTRODUCTION}

Word-Of-Mouth (WOM) has gotten more and more attention nowadays. The growing popularity of Internet sites, where users may discuss their feelings about companies and products, allows WOM information to proliferate in all aspects. Therefore, researchers and practitioners alike all want to know more about WOM. However, it is somewhat ironic that many marketers found that it is even more difficult to correctively estimate the effect of WOM. Some scholars have construed that WOM communication is the ultimate factor for product success (Day, 1971; Lan et al., 2012; Murray, 1991; Price and Feick, 1984), but other studies revealed that WOM communication is less effective than is often thought (O'Cass and Grace, 2004). Early Bansal and
Voyer (2000) had claimed that "there has been surprisingly little research conducted that has examined the effects of WOM communications on the receiver's purchase decisions". Nowadays, even though extensive efforts have been made to examine the effects of WOM (Chevalier and Mayzlin, 2006; Liu, 2006; Villanueve et al., 2008), its impact as reveal in different studies is still controversial. Several remarkable researches develop different models to capture the effects of WOM; however, research has found that the WOM dyad will adjust their behavior according to different level of perceived risk or in different situations. The dynamic and fuzzy natures of WOM communication have made it even difficult to correctively predict WOM effects; therefore, this study try to provide a more comprehensive approach to study WOM behavior.

Corresponding Author: Fangyi Liu, Department of Marine Leisure Management, National Kaohsiung Marine University, No.142, Haijhuan Rd., Nanzih Dist., Kaohsiung City 811, (R.O.C.), Taiwan 
Past research had confirmed many antecedents that heavily affect the effects of WOM. This study merely focuses on the relationship between perceived risk and WOM influence. Although the perceived risk is construed as a multidimensional phenomenon, most studies simply take it as an aggregated construct (Murray, 1991). However, Lin and Fang (2006) found that people respond differently to different risk dimensions. Moreover, evidence shows that consumers behave differently according to whether the situation is one of high or low influence. However, influence is a continuous variable, which cannot be described in the middle gray area. Because of the subjective cognition on risk attributes and the fuzziness on WOM influence in perceived-risk judgment, consumers feel uncertain in purchasing products or service. This study examined the effects of perceived risk on the receiver of WOM communication. WOM influence is a venture variable, which cannot be measured directly; the influence degree should be measured according to the effect factors of the WOM influence. So there is different influence degree in different situations. The influence degree is often roughly divided into "high influence" and "low influence" (Chevalier and Mayzlin, 2006). However, the influence degree is a continuous variable, not a "high" or a "low" variable. What is "high" influence and what is "low" influence is often ambiguous. Moreover, the human beings' fuzzy cognition can't be reflected this way. To deal with the vague linguistic phenomenon, Zadeh (1975) proposed fuzzy set theory with a membership function associated with each object. Therefore, in our study, we use the fuzzy mathematics to measure the consumers' influence. Fuzzy set theory is developed for solving problems in which description of activities and observations are imprecise, vague and uncertain.In this study, we present a fuzzy set approach to measure the WOM influence in consumers' perceived risks. The aim of this study is to obtain a better understanding of the consumers' preferences through the analysis of WOM communication in the risks and then offer the strategies of reducing consumers' WOM communication in risks among the attributions and dimensions with various risky cognitions.

\subsection{Theoretical Background}

Any choice involves risk when the consequences are associated with the decisions that are uncertain, even though some decision outcomes are desirable for customers. Whether decision consequences meet the customers' expectations and requirements is the key to the presence of perceived risk (Yilmaz and Flouris, 2010). In other words, what the consumers want is how to maximize their satisfaction and how to minimize their risks. In the decision model, perceived risk incorporates the primary dimensions of "uncertainty" and "dissatisfaction", but what "perceived risk" emphasizes is not a real risk that one can feel or receive. Dobromirov et al. (2011) deal with sovereign risk, market volatility, inflation rate, market liquidity and corruption level consider several major risk factors important for international portfolio investors willing to diversify their portfolio by investing in emerging markets. Every customer has an individual tolerance to risks (Demir and Bostanci, 2010; Rezaie et al., 2007). When the limit of tolerance is reached, the customer will either abandon the whole purchasing process, or they will find every possible way to reduce risks. Riskreduction or risk-avoidance strategies are used to describe the process by which customers seek to reduce the uncertainty or consequences of an unsatisfactory decision. Obtaining additional information usually reduces uncertainty.

The consumers want is how to maximize their satisfaction and how to minimize their risks. Generally, in the decision model, risk incorporates the primary dimensions of "uncertainty" and "dissatisfaction", but what "perceived risk" emphasizes is not a real risk that one can feel or receive. The perceived risk has beenconceptualized as a dual-component (consequences and uncertainty) multidimensionalphenomenon. Six dimensions of WOM in perceived-risk have been identified in Lin and Fang (2006). They are: (1) performance risk (the consumer's perceived risk that the functional attributes of the product donot satisfy his/her needs); (2) financial risk (the financial loss in case of poorwarranty, high maintenance costs and/or high monthly payments); (3) physicalrisk (how the purchase may affect the consumer's physical wellbeing); (4) temporal risk (the possibility that the consumer would have to waste a lot oftime and effort getting the product adjusted and repaired); (5) social risk (howthe purchase might affect what the consumer's friends and acquaintances thinkof him/her); and (6) psychological risk (how the purchase may affect what theconsumer thinks of himself or herself). 
Past research assumed that people would react in exactly thesame way to any risk dimensions (Murray, 1991). However, Wangenheim and Bayon (2004) found that, in high-risk situations, the higher the expertise and the similarity, the higher the effect of WOM information. They implied that consumers will respond differently to different risk dimensions; yetthe results of the study confirmed that both types of perceived risk are positivelyrelated to WOM influence. Beisswanger et al. (2003) suggested that people might take morerisks when advising or deciding for others, rather than for themselves, as theydo not have to suffer directly the possible negative consequences, such as fear ofrejection. Lin and Fang (2006) confirmed that when making a high-risk decision, either for themselves or for others, people are more likely to consider the potentialnegative outcomes. Accordingly, they regression analysis of 675 questionnaires administered inTaiwan metropolitan areas confirmed that financial risk and performance risk have significantpositive effects on WOM influence of the receiver's purchase decision, whereas social riskand psychological risk have significant positive effects on the sender's intention of WOMspread.

Moreover, Jia et al. (1999) focused on the expected model and probability distribution to evaluate the customers overall perceived risks, but they could not solve problems in which descriptions of activities and observations are imprecise, vague and uncertain. Since the decision process in which the consumers purchase their products or service involves the characteristic of quality, vagueness of human thought, cognition andperception, it is inappropriate to use precise and numerical data to evaluate the perceived risk in WOM influence. Therefore, we propose to examine the complex problems with a fuzzy process model, which can easily integrate and express the customers' perceived risk in WOM influence with linguistic variables.

\subsection{WOM Influence Fuzzy Measure}

In this research, the fuzzy measure combined the approaches of Chen (2002); Tsaur et al. (2002) and Hsu (1999) and to approach that is given as follows.

\subsection{WOM Fuzzy Influence Definition}

WOM influence is a fuzzy set; it contains a family of pairs $\left(\mathrm{A}_{\mathrm{i}}, \mu_{\mathrm{Ai}}(\mathrm{y})\right)$. WOM fuzzy influence is defined as Equation (1): $\mu$ minfluence $=\left\{\left(\mathrm{Ai}, \mu_{\mathrm{Ai}}(\mathrm{y}) \mid \mu_{\mathrm{Ai}} \rightarrow[0,1]\right\}, \forall \mathrm{y} \in \mathrm{Ai}, \mathrm{i} \in \mathrm{I}\right.$

Where:

$\mathrm{Ai}=\mathrm{A}$ fuzzy set for WOM influence factor $\mathrm{i}$

$\mathrm{y}=\mathrm{A}$ WOM influence fuzzy grade for factor $\mathrm{i}$

\subsection{Fuzzy Measure Process on WOM Influence}

Step1: Design the questionnaire containing the fuzzy linguistic scale

First, we design a set of the linguistic terms of the questionnaire. Then, we assign all the linguistic terms as crisp scores. The set of linguistic terms we adopt in our research is agree very much, agree, agree a little, not agree, never agree $\}$ and the score range from 0 to 100 . Each linguistic term is given a value. The values obtained are used to set up the fuzzy numbers of the linguistic terms.

Step2: Build the membership function of linguistic terms.

We use the method of group aggregation by $\mathrm{Hsu}$ (1999) to build the membership function of the linguistic terms (Fig. 1). Hsu's method can improve the weakness of the traditional Delphi method with the iterative procedure.His method of group aggregation is as Equation 2:

$$
\begin{aligned}
& \mathrm{P}=(1, \mathrm{~m}, \mathrm{u}) \\
& \mathrm{l}=\operatorname{Min}\left(\mathrm{P}_{\mathrm{i}}\right), \mathrm{i}=1,2, \ldots, \mathrm{n} . \\
& \mathrm{m}=\left(\prod_{i=1}^{\mathrm{n}} \mathrm{P}_{\mathrm{i}}\right)^{1 / \mathrm{n}}, \mathrm{i}=1,2, \ldots, \mathrm{n} \\
& \mathrm{u}=\operatorname{Max}\left(\mathrm{P}_{\mathrm{i}}\right), \mathrm{i}=1,2, \ldots, \mathrm{n}
\end{aligned}
$$

Where:

$\mathrm{P}_{\mathrm{i}}=$ WOM receiver $\mathrm{i}$ opinion, $\mathrm{i}=1,2, \ldots, \mathrm{n}, \mathrm{Pi}>0$

$\mathrm{P}=$ Membership functions of linguistic terms

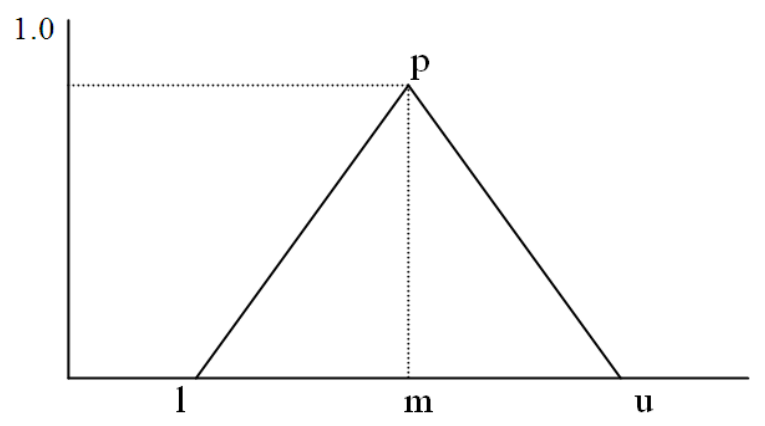

Fig. 1. Membership functions of linguistic terms 
Step3:Build the membership function of the WOM influence factors

If the consumers choose "never agree" in the questionnaire, this implies that the membership degree of influence is 0 . If they choose the linguistic term "agree very much," this implies that the membership degree of influence is 1 . The interval value of the term "never agree" is from 0 to $b$. The grade belonging to "never agree" is 1 . When the interviewee gives the score higher than a, it means the interviewee starts involving the purchase. So $a$ is defined as the beginning point of influence. In the same way, the interval value of the term "agree very much" is from $\mathrm{d}$ to e. When the score is higher than e, the grade belonging to "agree very much" is 1 . When the interviewee gives the score higher than e, it means the interviewee involves the purchase completely. So e is defined as the point of complete influence (Fig. 2).

The membership functions of fuzzy set are defined as Equation (3):

$$
\mu \text { factor }(y)=\left\{\begin{array}{cc}
0 & y \leq a \\
(y-a) /(e-a) & a<y<e \\
1 & y \geq e
\end{array}\right.
$$

Where:

$\mathrm{y}=$ Average grade of influence factors in questionnaire

$\mathrm{a}=$ The beginning point of WOM influence

$\mathrm{e}=$ The point of complete WOM influence

\section{Step 4: Aggregation operators}

We adopt the compensation aggregation operator, $\gamma$ operator, put forward by Zimmermann and Zysno (1980). We set the range of compensation $\gamma=0.5$, because the factors can not compensate for each other when $\gamma$ is 0 . When $\gamma=1$, they can compensate completely.

Step 4-1: WOM influence for single receivers and multiple factors

We should aggregate the "WOM important" with the "WOM interest" in the aggregation operators. Therefore, we could get the synthetic index of the enduring influence. In the same way, we could get the synthetic index of the situation influence by aggregating the risk factors. Finally, we combine the enduring influence and the situation influence and get the influence for the single WOM receivers and multiple factors is as Equation (4):

$$
\begin{aligned}
& \mu_{\mathrm{i}}(\mathrm{y})=\left\{\prod_{\mathrm{i}=1}^{\mathrm{n}}\left(\mu_{\mathrm{Ai}}(\mathrm{y})\right)^{\sigma \alpha i}\right\}^{1-\gamma}
\end{aligned}
$$

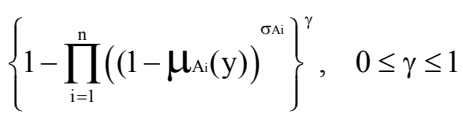

Step 4-2: Aggregation operators in multiple consumers and multiple factors

Utilize Equation (5) to get the synthetic index of influence for single factor and multiple consumers:

$$
\begin{aligned}
& \mu_{\text {Involvement }}(y)=\left\{\prod_{j=1}^{n}\left(\mu_{j}(y)\right)\right\}^{1-\gamma} \\
& \left\{1-\prod_{j=1}^{n}\left(1-\mu_{j}(y)\right)\right\}^{\gamma}, 0 \leq \gamma \leq 1
\end{aligned}
$$

$\mu_{\text {Involvement }}(\mathrm{y})=$ Synthetic index in multiple WOM receivers and multiple factors

$\mu_{\mathrm{i}}(\mathrm{y}) \quad=$ Synthetic index in multiple factors of WOM receiver $\mathrm{j}$

$\mathrm{n}=$ The number of WOM receivers

Step 4-3: Aggregation operators in multiple consumers and single factor

To gain more information of WOM receivers, we use Equation (6) to get the influence of multiple WOM receivers to each factor:

$$
\begin{aligned}
& \bar{\mu}_{\tilde{A i}(\mathrm{y})}=\left\{\prod_{\mathrm{j}=1}^{\mathrm{n}}\left(\mu_{\tilde{A}_{\mathrm{ij}}(\mathrm{y})}\right)\right\}^{1-\gamma} \\
& \left\{1-\prod_{\mathrm{j}=1}^{\mathrm{n}}\left(1-\mu_{\tilde{\mathrm{A}} \mathrm{ij}}(\mathrm{y})\right)\right\}^{\gamma}, 0 \leq \gamma \leq 1
\end{aligned}
$$




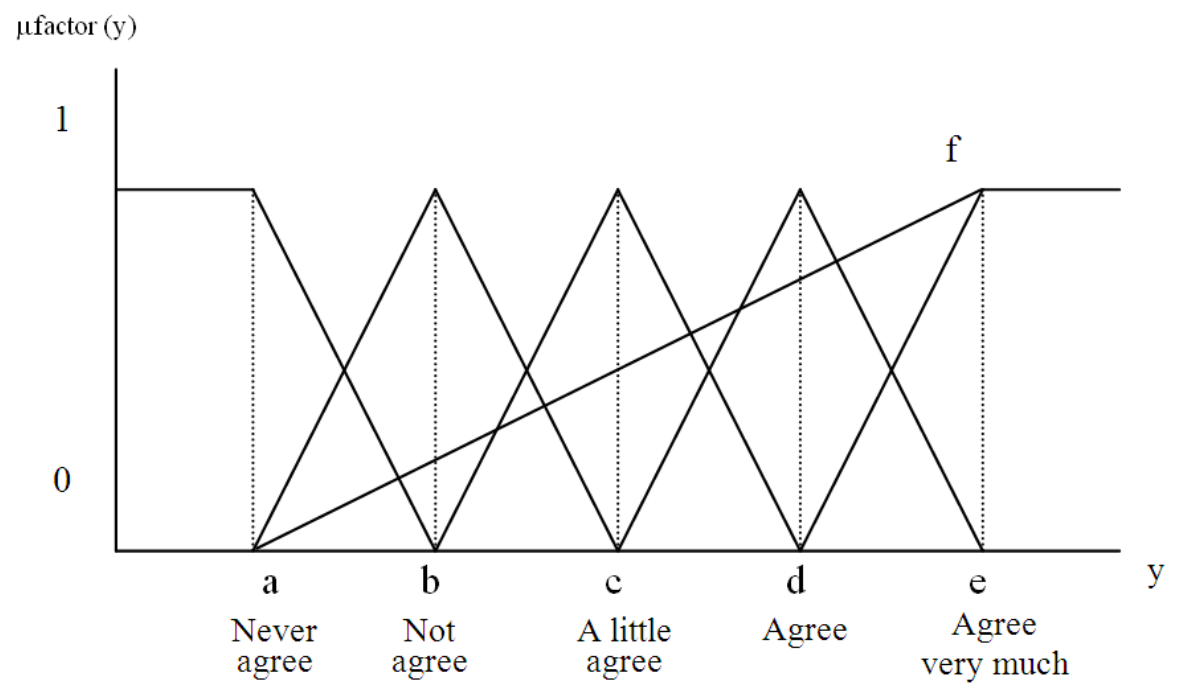

Fig. 2. Membership function of the WOM influence factors

\section{MATERIALS AND METHODS}

\subsection{Instrument}

Based on the questionnaires by Hsu and Lin (2006) and Lin and Fang (2006), we developed a questionnaire for consumers. This questionnaire included 20 questions on WOM in risks and background information. With travel agents' assistance of ecotourism, the questionnaire was carefully examined and advised upon, giving it high validity.

The factors to be measured for WOM influence include (1) factors of WOM enduring influence, which contain the WOM importance of the product or service (for example, WOM in products or service benefits and its value) and the continuous WOM interest (for example, a WOM ongoing concern with products or service); (2) factors of WOM situational influence, which contain functional risk, financial risk, psychological risk, physical risk, social risk and temporal risk. Two alternative-form reliability tests were conducted using the statements, "Your ecotourism operator may add a surcharge, although the brochure said there would be none", "You may be charged more for the travel by your ecotourism operator", where Pearson's $r=0.76$.

\subsection{Sample and Characteristic of Ecotourism Customers}

Ryu and Feick (2007) suggested that influence of WOM should be measured in a industry product with less self-control, variety and give more service to ensure the validity of the questionnaire. Thus, the ecotourism industry was chosen for this study to measure perceived risk in WOM influence. The Taiwanese ecotourism sector is starting to develop. This study defined the ecotourism industry as: The travel built on the basis of natural resources, humane history and geographical relics while taking environment protection, environment education and local profit as its final objective with the aim to achieve permanent development (Cardenas-Torres et al., 2007; Gifford et al., 2007; Lee et al., 2011; Lindsey et al., 2007).

The sampling period was selected during April 2012. The sampling locations included several major well-known ecotourism scenicspots in Taiwan. In addition, with the assistance of local ecotourism representatives, we asked customers who stay in wellknown ecotourism scenicspots to fill out the questionnaire and they could not fill out the questionnaire more than once. There were a total of 218 questionnaires of which 200 were usable (Table 1).

The respondents ranged in age from 18 to 70 years old and the ratio of male/female was roughly equal.

\section{RESULTS}

\subsection{Influence Membership Function}

From the questionnaire survey, we build the influence membership function, shown in Fig. 3. 


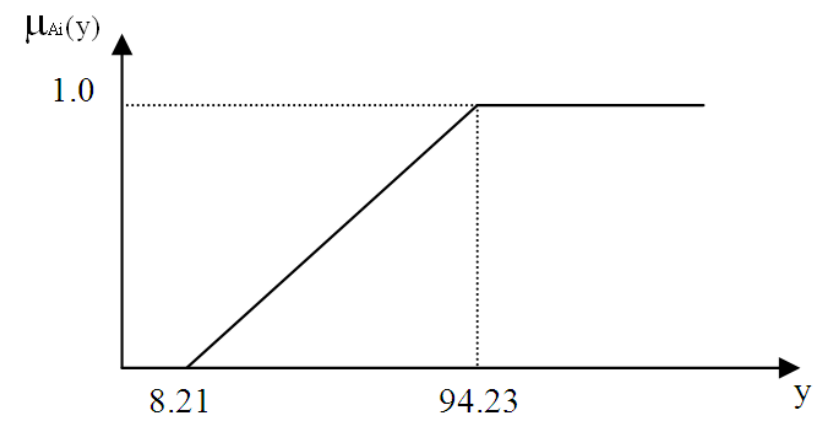

Fig. 3. WOM influence membership function

Table 1. Cross-table analysis between frequencies of ecotourism average expenditure

\begin{tabular}{|c|c|c|c|c|c|}
\hline \multirow{2}{*}{$\begin{array}{l}\text { Frequency of } \\
\text { join ecotourism }\end{array}$} & \multicolumn{5}{|c|}{ Average expenditure (US\$) } \\
\hline & Below 100 & $100-200$ & $200-300$ & 300 above & Total \\
\hline Once & & & & & 28 \\
\hline Count & 26.0 & 2.0 & & & \\
\hline Sum $(\%)$ & 13.0 & 1.0 & & & \\
\hline Two & & & & & 32 \\
\hline Count & 26.0 & 5.0 & 1.0 & & \\
\hline Sum $(\%)$ & 13.0 & 2.5 & 0.5 & & \\
\hline Three & & & & & 46 \\
\hline Count & 17.0 & 18.0 & 11.0 & & \\
\hline Sum $(\%)$ & 8.5 & 9.0 & 5.5 & & \\
\hline Four & & & & & 48 \\
\hline Count & 14.0 & 19.0 & 13.0 & 2.0 & \\
\hline Sum $(\%)$ & 7.0 & 9.5 & 6.5 & 2.0 & \\
\hline More than four & & & & & 46 \\
\hline Count & 8.0 & 13.0 & 16.0 & 9.0 & \\
\hline Sum $(\%)$ & 4.0 & 6.2 & 8.0 & 4.5 & \\
\hline Total & & & & & \\
\hline Count & 91.0 & 57.0 & 41.0 & 11.0 & 200 \\
\hline Sum $(\%)$ & 45.5 & 28.5 & 20.5 & 5.5 & 100 \\
\hline
\end{tabular}

Table 2. WOM fuzzy influence in multiple consumers and multiple factors

\begin{tabular}{|c|c|c|}
\hline & WOM enduring & WOM situational \\
\hline $\begin{array}{l}\text { Membership } \\
\text { function of factors }\end{array}$ & 0.6304 & 0.5677 \\
\hline $\begin{array}{l}\text { WOM influence } \\
\text { degree of ecotourism }\end{array}$ & 0.5484 & \\
\hline
\end{tabular}

When the beginning point of WOM influence is 8.21 and the point of complete WOM influence is 94.231 , the WOM membership function is:

$$
\mu_{\mathrm{Ai}}(\mathrm{y})=\left\{\begin{array}{cc}
0 & y \leq 8.21 \\
\frac{\mathrm{y}-8.21}{94.23-8.21} & 8.21<y<94.23 \\
1 & y \geq 94.23
\end{array}\right.
$$

Table 3. Fuzzy influence in all factors

\begin{tabular}{lll}
\hline WOM enduring influence & WOM Important & 0.5371 \\
& WOM Interest & 0.8024 \\
WOM situational influence & Functional risk & 0.6922 \\
& Financial risk & 0.8521 \\
& Psychological risk & 0.9344 \\
& Physical risk & 0.3126 \\
& Social risk & 0.2913 \\
& Temporal risk & 0.5953 \\
\hline
\end{tabular}

Multiple consumers and multiple factors of WOM fuzzy influence.

From Table $\mathbf{2}$ we find that the interviewees are more interested in WOM enduring influence than in situational influence. 


\subsection{Multiple WOM Fuzzy Influence Factors}

From Equation 6, we can get Table 3. In WOM enduring influence, the interest for the WOM of ecotourism is more important than their WOM benefits offered. The result reflects that we can infer the WOM influence from the ecotourism characteristics. In WOM situational influence, the financial and functional risks are higher than other factors. The psychological risk is higher than other factors.

\section{DISCUSSION}

In this study we define the mathematics meaning of the influence and develop a new method to build the membership function to measure the perceived risk in WOM Influence. In this new method, we can exactly measure the WOM influence. For example, we say that the "influence is 0.8 " or "the influence is 0.1 ", instead of "high influence" or "low influence". This new method can help marketing managers better understand the consumer decision making process. The conclusions could be used as a reference for ecotourism agents and the managers in the ecotourism industry to understand consumers' needs. Throughout this study, we have been able to clearly see the division among the risk attributes in WOM communication, upon which consumers put emphasis. The results reveal that the dominant strategies about asking family or friends for advice and purchasing ecotourism insurance in the financial and functional risks are highly serious. Consumers in this quadrant like to ask their friends and family for travel advice and information. Moreover, they think purchasing insurance can reduce the loss and increase the guarantee.

\section{CONCLUSION}

About financial-functional Cognition: In our finding, it is important of WOM receivers. The ecotourism agency should avoid go bankrupt, don't charge additionally for visiting activities and charge excessively for telephone calls. Besides, chose better ecotourism location is important. From the fuzzy synthetic index of WOM influence, we can understand the membership grade for each influence factor, which reflects the WOM revivers' preference cognition and value. It can help marketing managers to predict the consumer behavior and to design the marketing mix to meet the consumers' needs and wants. The fuzzy synthetic index of WOM influence can calculate the individual person's influence. From this, we can build a database of the perceived risk in WOM Influence.

\section{ACKNOWLEDGEMENT}

We would like to thank the anonymous referees for their valuable comments and suggestions.

\section{REFERENCES}

Bansal, H.S. and P.A. Voyer, 2000. Word-of-mouth processes within a services purchase decision context. J. Serv. Res., 3: 166-177. DOI: 10.1177/109467050032005

Beisswanger, A.H., E.R. Stone, J.M. Hupp and L. Allgaier, 2003. Risk taking in relationships: Differences in deciding for oneself versus for a friend. Basic Appl. Soc. Psychol., 25: 121-135. DOI: 10.1207/S15324834BASP2502_3

Cardenas-Torres, N., R. Enriquez-Andrade and N. Rodriguez-Dowdell, 2007. Community-based management through ecotourism in Bahia de Los Angeles, Mexico. Fish. Res., 84: 114-118. DOI: 10.1016/j.fishres.2006.11.019

Chen, J.H., 2002. Venture capital companies investing high-tech industry by fuzzy multi-criteria methods: Biology industry as example. Fu Jen Manage. Rev., 9: 87-110.

Chevalier, J.A. and D. Mayzlin, 2006. The effect of word of mouth on sales: Online book reviews. J. Market. Res., 43: 345-354. DOI: 10.1509/jmkr.43.3.345

Day, G.S., 1971. Attitude change, media and word of mouth. J. Adv. Res., 11: 31-40.

Demir, H. and B. Bostanci, 2010. Decision-support analysis for risk management. Afr. J. Bus. Manage., 4: $1586-1604$.

Dobromirov, D., M. Radisic and A. Kupusinac, 2011. Emerging markets arbitrages' perception: Risk versus growth potential. Afr. J. Bus. Manage., 5: 713-721.

Gifford, A., Compagno, L.J.V., M. Levine and A. Antoniou, 2007. Satellite tracking of whale sharks using tethered tags. Fish. Res., 84: 17-24. DOI: 10.1016/j.fishres.2006.11.011

Hsu, T.H. and L.Z. Lin, 2006. Using fuzzy set theoretic techniques to analyze travel risk: An empirical study. Tour. Manage., 27: 968-981. DOI: 10.1016/j.tourman.2005.10.022 
Hsu, T.H., 1999. Public transport system project evaluation using the analytic hierarchy process: A fuzzy Delphi approach. Transpor. Planning Technol., 22: 229-246. DOI: 10.1080/03081069908717630

Jia, J., J.S. Dyer and J.C. Butler, 1999. Measures of perceived risk. Manage. Sci., 45: 519-532.

Lan, M.Y., Liu, F., Fang, C. H. and T. M. Y. Lin, 2012. Understanding word-of-mouth in counterfeiting. Psychology, 3: 289-295. DOI: 10.4236/psych.2012.33041

Lee, M.S., Y. Han and Y.R. Hsu, 2011. A study of the key success factors of the ecotourism industry in Taiwan. Afr. J. Bus. Manage., 5: 627-640.

Lin, M.Y. and C.H. Fang, 2006. The effects of perceived risk on the word-of-mouth communication dyad. Soc. Behav. Pers., 34: 1207-1216. DOI: 10.2224/sbp.2006.34.10.1207

Lindsey, P.A., P.A. Roulet and S.S. Romanach, 2007. Economic and conservation significance of the Trophy Hunting Industry in Sub-Saharan Africa. Biol. Conserv., 134: 455-469. DOI: 10.1016/j.biocon.2006.09.005

Liu, Y., 2006. Word of mouth for movies: Its dynamics and impact on box office revenue. J. Market., 70: 74-89. DOI: $10.1509 /$ jmkg.70.3.74

Murray, K.B., 1991. A test of services marketing theory: Consumer information acquisition activities. J. Market., 55: 10-25. DOI: 10.2307/1252200

O'Cass, A. and D. Grace, 2004. Service brands and communication effects. J. Market. Commun., 11: 241-54. DOI: 10.1080/1352726042000228286

Price, L.L. and L.F. Feick, 1984. The role of interpersonal sources in external search: An informational perspective. Adv. Consum. Res., 10: 250-255.
Rezaie, K., M.S. Amalnik, A. Gereie, B. Ostadi and M. Shakhseniaee, 2007. Using extended Monte Carlo simulation method for the improvement of risk management: Consideration of relationships between uncertainties. App. Math. Comput., 190: 1492-1501. DOI: 10.1016/j.amc.2007.02.038

Ryu, G. and L. Feick, 2007. penny for your thoughts: Referral reward programs and referral likelihood. J. Market., 71: 84-94. DOI: 10.1509/jmkg.71.1.84

Tsaur, S.H., T.Y. Chang and C.H. Yen, 2002. The evaluation of airline service quality by fuzzy MCDM. Tour. Manage., 23: 107-115. DOI: 10.1016/S0261-5177(01)00050-4

Villanueve, J., S. Yoo and D.M. Hanssens, 2008. The impact of marketing-induced versus word-of-mouth customer acquisition on customer equity growth. J. Market. Res., 45: 48-59.

Wangenheim, F.V. and T. Bayon, 2004. The effect of word of mouth on services switching: Measurement and moderating variables. Eur. J. Market., 38: 11731185. DOI: 10.1108/03090560410548924

Yilmaz, A.K. and T. Flouris, 2010. Managing corporate sustainability: Risk management process based perspective. Afr. J. Bus. Manage., 4: 162-171.

Zadeh, L.A., 1975. The concept of a linguistic variable and its application to approximate reasoning. Inform. Sci., 8: 199-249. DOI: 10.1016/00200255(75)90036-5

Zimmermann, H.J. and P. Zysno, 1980. Latent connectives in human decision making. Fuzzy Sets Syst., 4: 37-51. DOI: 10.1016/0165-0114(80)900627 